\title{
Research on the Development Characteristics and Trend of the Smart Terminal Industry in Henan Province
}

\author{
Xi Niu \\ Zhengzhou Institute of Aeronautics Industry Management \\ Zhengzhou, China, 450007
}

\begin{abstract}
With the rapid development of the global smart terminal industry, and China's broadband and Internet technology industry, Henan, as a big production province of smart terminal products, is also developing rapidly in mobile smart terminal market, and has become the absolute backbone of the global smart terminal industry in growth. In 2015 Henan mobile smart terminal manufacturers are trying to build an independent industry ecosystem in order to improve the vertically integrated development model, strengthen the research and development of communication chip processing technology, and actively respond to the opportunities and challenges of China's mobile smart terminal industry chain.
\end{abstract}

Keywords-smart terminal; industrial status; development prospects

\section{INTRODUCTION}

At present, according to the definition of International Research Institute of Internet Data Center, there are four categories of smart terminal products, including PC and PC extended products, smart devices and smart phones. 2015 is a year with high-speed integration of China's smart terminal products. The smart terminal products flow towards lowerlevel cities. The changes of product channel pattern, the impact of smart phones and tablet PCs on PC and other factors have produced the most dramatic reaction in 2015 since the beginning of history. The smart terminal products manufacturers are gradually being changed by the market.

\section{THE DEVELOPMENT ST ATUS OF THE SMART TERMINAL INDUST RY}

\section{A. The Development Characteristics of China's Smart Terminal Industry}

At present the industry has entered into a stage of largescale popularization of smart terminal products. The terminal industry itself has a great change, and it has triggered a disruptive change in the entire ICT industry. It has led to the integration of manufacturing and service innovation and cross-border integration, which has a profound impact on the entire information and communication industry. With four

\footnotetext{
Fund Programs: Tender Subject of Henan Provincial Government Decision Research in 2015, №2015B120

2014 Zhengzhou Instit ute of Aeronautical Industry Management Youth Fund, №2014142002
}

basic characteristics of open operating system platform, PC processing capacity, high-speed data network access capabilities and plenty of HCI interfaces, the smart terminal products have been extended from smart phone, tablet computer into smart TV, wearable device, automotive electronics and so on. In general, we have accumulated a wealth of experience on whole machine manufacturing and OEM. However, we are still weak in key links, such as basic software and important components.

\section{B. The Development Characteristics of the Smart Terminal Industry in Henan Province}

Henan has obvious advantages of production cost factors. With development in these years, Henan has a relatively complete production system and a strong supporting capacity. With the accelerating construction of Zhengzhou Airport Economic Comprehensive Experiment Zone, comprehensive transportation, modern logistics and other aspects of the conditions are significantly improved, and the ability to undertake industrial transfer has been improved step by step. We can not transfer one or two smart terminal enterprise, because they need to develop in a collective manner and produce in cluster mode. In this way they can form an industrial system with professional work division and efficient teamwork. So overall, Henan, especially Zhengzhou has relatively good conditions for the development of smart terminal industry. For Henan, it is a major and vital event to undertake industrial transfer and develop smart terminal industry, rather than simply attracting foreign businessmen and investment. Henan Provincial Party Committee and Provincial Government will attach great importance to the development of the smart terminal industry and treat the development of the smart terminal industry, as a strategic initiatives to realize the rise of Central China and the revitalization of Henan, enrich the people and strengthen the province, and at same time put it in an import position in the overall situation of Henan Province.

\section{THE COMPREHENSIVE DEVELOPMENT ANALYSIS OF SMART TERMINAL PRODUCTS IN HENAN PROVINCE}

Henan's smart terminal industry develops rapidly with the strong support of the state and Henan's provincial 
governments, but it is still primarily an OEM manufacturer in terms of the industrial scale. Seen from sales of brand terminal and upper software development, the overall strength of Henan industry chain and its potential is not optimistic. The current industry chain develops in a pigeon track. It is very weak in core links, such as operation system, core chip, and basis components. But the application industry and the OEM industry are relatively good. In this case, Henan's smart terminal manufacturers are dominant in the production capacity, but the leading degree of products is not so good. With limited profit space, it has not yet showed its brand advantage. Therefore, on the basis of current situation, we should give long-term consideration on the development of Henan's smart terminal industry. It has become an urgent major event to consider the support direction and development strategies of the government in next step.

\section{A. Lack of Core Technologies}

At this stage Henan's relevant smart terminal manufacturers' production technologies, involving in CPU, RF chip, sensor, interface-operating system, electronic components and etc., basically are controlled by foreign companies, so you can imagine our weak independent industrial ability. The domestic R\&D enterprises and institutions are lack of strength and experience in these key fields, so our products are always limited in the lower and middle-end markets, and we have not formed scale of application of our own products. Henan almost has no professional research team dedicated to the research of smart terminal products.

\section{B. Low Profit in Accessories Processing}

In 2015 domestic smart terminal products are still in a unfavorable status with high cost, high volume but low price and incomplete industrial chain, so we have low profitability, little appreciation ability and low rate of profit. In addition, nearly all key core technologies of smart terminal products are mastered by foreign enterprises. For example, only the RF chip manufacturer Qualcomm has occupied 94\% of 3G and 4G global chip market. Under influence of key technologies and market share, Henan's enterprises at present are still in the basic links, such as manufacturing, low-end processing and supporting.

\section{Serious Product Similarity Phenomenon}

With low threshold, there are hodge-podge smart terminal enterprises. They blindly imitate and follow each other, resulting in a serious product similarity phenomenon. Henan's independent manufacturing enterprises are mainly concentrated in the low-end market. They take imitation of cheap copy and low price with low profit as their survival weapon, so it is difficult for them to enter into the middle and high-end market. They stay in low-end market and fight with each other over price and ignore the definition of product and the original innovation. They simply understand brand construction as speculation. In addition, most of middle and small-sized smart terminal product enterprises are vague in the definition of brand. They follow the trend blindly, so their products are of varied quality. Core brands are lack of market competitiveness, and they always follow others in the market.

\section{THE DEVELOPMENT TREND OF CHINA'S SMART TERMINAL INDUST RY}

With combined action of the demand expansion of mobile users, healthy operation of macro economy, the rapid development of mobile Internet, maturity and openness of operating system and other related factors, our smart terminal industry develops at an unprecedented pace. At same time, the industry still faces many challenges. We need to seek solutions to these problems in the development. It is suggested to strengthen the layout of our mobile smart terminal industry in the following aspects.

First, promote the transformation of China's electronic manufacturing industry from productivity advantages into brand superiority with the mobile smart terminal as an opportunity, support domestic enterprises to carry out the R\&D of high-end products, and improve the added value of high-end products. Strengthen the guidance of existing highend oriented and large-scale smart terminal product enterprises, support domestic enterprises with strength to research and develop high-end oriented smart phones, tablet PCs, wearable devices and other products with powerful functions and high quality and provide good service. Encourage in-depth cooperation among manufacturers, software companies, and information service enterprises, to achieve full co-development. And carry out relevant policies and measures to promote consumption of domestic smart products and the application and popularity of domestic smart phones, tablet PCs and other smart terminal products.

Second, guide enterprises to develop multi-channel terminal marketing strategy, transform the fixed thinking mode of "operator central purchase" that enterprises rely on, and help them sell products with multi-channels, like internet, store and etc. At same time, strengthen the supervision on productivity, productivity utilization rate, production and sales quantity in stock, support enterprises to accelerate the pace of survival of the fittest, decisively phase out enterprises with backward production capacity, to avoid trapping in the low-end mire.

Third, incorporate smart TV and tablet PC into smart phone strategy and make the three-screen integrated design. Take smart TVs and tablet PCs as new key mobile terminal with smart phones in next two years, and promote the construction of terminal brand, application software and innovation of chip products with the view of three-screen overall plan. Encourage the integrative development of smart TV and smart phone, and support Internet companies and traditional TV manufacturers to carry out the integration of resources and mutual access with the methods, such as softening approval procedure.

Fourth, aim at the development direction of smart wearable device, use late-mover advantages to lead the development of medical and health devices. Do not follow the trend blindly or demand perfection. Do not give too much investment in new interactive smart wearable field in 
overheat period in case of working fruitlessly. In addition, take advantage of the demographic dividend and combine with the needs of national health care. Carry out innovation and development with cloud application of medical treatment and healthy smart wearable devices. Closely follow the development trend of international smart wearable devices to integrate domestic resource advantages. Actively use existing resources and reserves and follow the process of international new-type interactive smart wearable device.

\section{THE DEVELOPMENT PROSPECT S OF HENAN'S SMART TERMINAL INDUST RY}

In 2015, the smart terminal industry in Henan shall develop on the bas is of professional and technical innovation, take the innovation of industrial mode as power, always pay attention to brand building, meanwhile widen market channels actively, and establish the patent-sharing mechanis $m$ and the information security guarantee system in smart terminal industry to avoid international patent litigation and information security risks. At same time, take Zhengzhou Airport Economic Comprehensive Experimental Zone as the base of provincial smart terminal industry, and undertake the transfer of whole industrial chain of domestic smart terminal products and relevant products. Under this premise, sum up the following recommendations according to the existing comprehensive development direction.

\section{A. The Establishment of Patent Pool}

Currently most of Henan's smart terminal product enterprises do not have the independent patent rights of key core technologies. It is suggested to establish the patent pool mechanis $m$ in order to avoid increasingly fierce international patent lawsuit in the smart terminal products fields and actively respond patent litigation. We can help Henan's enterprises increase the depth of cooperation and integrate domestic and foreign core patent resources, and establish smart terminal product patent pool safebox and other types of platforms to realize share of patent in a small range with the aid of relevant associations and institutions. We can also establish a provincial patent attack and defense legal aid team to help our s mart terminal manufacturers solve disputes in product patent and intellectual property rights.

\section{B. The Implementation of Research and Innovation}

Give greater efforts to promote the R\&D of key technologies and focus on the R\&D of multi-mode multiband baseband and RF chip, dual/multi-core application processor (AP) with high processing power, DIPER/GPS/GLONASS satellite navigation and positioning multimode receiver chip, MEMS and low-temperature polysilicon (LTPS), active matrix and organic light emitting diode (AMOLED) display and other key components, and the industrialization in order to gain achievements of a number of independent intellectual property rights in the upstream of the industry. In support of $R \& D$ and industrialization projects, emphasize the prospects and guidance, guide enterprises to pay close attention to the new internal trend in new-type $\mathrm{HCI}$ and newly-developing product forms of smart phone technology innovation and make a good layout in technology and provincial industry in advance[5].

\section{The Encouragement of the Production Innovation}

Encourage the production innovation and take market demand as the direction in order to increase the added value of products. Attach great importance to the development of application services and other non-core technical aspects, such as APP for s mart phones and application service setting, in order to meet the various needs of users, and accelerate innovation upon the user experience. Take full use of the opportunities of information and urbanization construction in Henan and central and western regions and vigorously dig the diverse needs of urban and rural consumers, and mainly take differential strategy in order to compete with foreign companies and domestic similar companies with different function design, craftsmanship appearance, service model and etc.

\section{The Implementation of the Superior Policy}

Beginning in 2015, from the formulation and implementation of relevant policies of Henan Provincial Government it can be seen that the governments support the smart terminal industry. It is inseparable from the strongly support of relevant leading cadres of Henan Province and Zhengzhou Airport Zone to cultivate our own provincial superior industrial chain in the smart terminal industry. It has an important significance to make big and strong key enterprises in an acceleration way, guide transfer of industry reasonably and orderly, improve the development level of industrial cluster, guide key enterprises toward the industrial chain, carry out vertical integration, coordinate the upstream with the downstream, and create a good industrial environment for "chip - system - terminal - application". At same time, take superior policy to attract small and middlesized smart terminal manufacturers for cooperative research and development, innovate to drive regional transformation and upgrading, and build Henan smart terminal industrial chain.

\section{CONCLUSION}

In 2015 the development of s mart terminal industry in Henan has entered a new phase. The smart terminal industry has increase the weight of speech in global industrial chain. In the face of fast-growing emerg ing market demand and the improvement of product margins and other opportunities, Henan, as a big smart terminal industrial province, are struggling to meet the greater challenges and opportunities for development under merger and integration of terminal markets and an increasingly competitive environment.

\section{REFERENCES}

[1] $\mathrm{Xu}$ Yongde. Evaluation System Triggered by Industrial Characteristics. Cloud Industry Watch. Science and Technology Management Research. Reform, 2015 (02).

[2] Hu Pinping. Research on Development Strategy of Mobile Smart Terminal Industry on the Basis of Patent Analysis, 2014 (13). 
[3] Huang Wei. Research on the Development Characteristics and Trend of Smart Terminal Industry. ICT, 2014 (04).

[4] Wang Qiong. Study on the Development of Smart Terminal Industry under Mobile Internet. Modern Telecommunications Technology, 2014 (06).

[5] Jesse James Garrett. Customer Loyalty and the Elements of User Experience. Design Management Review, 2010 (01).

[6] CCID of The Ministry of Industry and Information Technology. White Paper of Development of Mobile Smart Terminal Industry. China Electronic Information Development Institute, 2015 (04). 